\title{
Analysis of Medical Waste Incinerator Performance Based on Fuel Consumption and Cycle Times
}

\author{
Samwel Victor Manyele, Ignatio Simon Kagonji \\ Department of Chemical and Mining Engineering, Collage of Engineering and Technology, \\ University of Dar es Salaam, Dar es Salaam, Tanzania \\ Email: smanyele@udsm.ac.tz,kagonji@yahoo.com
}

Received August 2, 2012; revised September 1, 2012; accepted September 11, 2012

\begin{abstract}
A detailed assessment of an incinerator based on fuel consumption and cycle time data is presented in this paper. The study was conducted at Temeke district hospital for 22 months consecutively covering 654 days of daily data collection on waste loading rate fuel consumption and cycle times. The composition for the medical waste incinerated varied between $15 \%$ and $35 \%$ for sharps waste and between $65 \%$ and $85 \%$ for other waste, with mean values of $25 \%$ and $75 \%$, respectively. The results revealed poor performance of the incinerator due to higher fuel consumption (above 30 $\mathrm{L} /$ cycle). The incineration cycle times were observed to range between 2 and 4 hours, all of which were too high for the loading rates observed (55 - $214 \mathrm{~kg}$ ). A strong dependency of diesel oil consumption on cycle time was observed due to lack of temperature control leading to continuous fuel flow into the burners. The incineration capacity was very low compared to other incinerators in terms of tons per year. This paper gives an insight on the factors affecting incinerator performance assessed based on diesel oil consumption and cycle times. It can be generalized that the incinerator performance was poor due to several factors ranging from poor incinerator design, operator skills, waste management practices, waste storage practices, etc. The hospital was advised to install a new incinerator with short incineration cycle time (30 - 40 minutes) and lower fuel consumption (10 L/cycle) at a loading rate of $200 \mathrm{~kg} /$ cycle.
\end{abstract}

Keywords: Waste Combustion; Incinerator Performance; Medical Waste Incineration; Fuel Consumption; Incineration Cycle Time; Sharps Waste; Incinerator Capacity; Fuel Effectiveness

\section{Introduction}

This paper gives more insight to hospitals on the medical waste incineration process, and its major challenges, in particular fluctuations in fuel consumption and incineration cycle time. Medical wastes incinerated were segregated in two categories: sharps waste (containing needles, syringe and surgical blades). The other waste category included all waste such as pathological waste (human tissues, organs and body fluid), pharmaceutical waste (drugs, vaccines spoiled or expired), and chemical waste (detergents, dressing solutions), grouped together.

\section{Literature Review}

\subsection{Incineration Background}

This study involved assessment of the medical waste incineration which is a thermal waste treatment process that involves the combustion of organic substances contained in the waste materials at higher temperatures $\left(850^{\circ} \mathrm{C}-1000^{\circ} \mathrm{C}\right)$, a process which takes too long if the incinerator is not well designed and operated. The incineration process detoxifies medical waste by destroying most of the organic compounds contained in it and reduces the volume and weight of the waste leading to inert residual of solids, with an appreciable amount of fuel being consumed.

Incineration of medical waste converts the waste into essentially non-combustible solid residue or ash [1-4]. Other outputs include flue gas and heat. The ash is mostly formed by the inorganic constituents of the waste, and may take the form of solid lumps or particulates that can also be carried by the flue gas $[1,2,4]$. Thus, the flue gases must be cleaned of gaseous and particulate pollutants before they are dispersed into the atmosphere. In some cases, the heat generated by incineration can be recovered and used to generate hot water or electric power. The need to convert heat into power is critical in order to off-set fuel consumption costs. Waste incineration with energy recovery is one of several waste-to-energy (WtE) technologies such as gasification, pyrolysis and anaerobic digestion. For environmental protection purposes, incineration may also be implemented without energy recovery $[5,6]$.

The main advantage of incineration over all other 
methods is the volume reduction, which is important in cities where space is scarce and landfill plots are not available. Incinerators reduce the solid mass of the original waste by $80 \%$ - $85 \%[7,8]$ and the volume (already compressed somewhat in garbage trucks) by $95 \%$ - 96\%, depending on composition and degree of recovery of materials such as metals from the ash for recycling. This means that while incineration does not completely replace landfilling, it significantly reduces the necessary volume for disposal [9]. Incineration reduces the volume considerably but does not completely solve the problem because the ash that remains after the process must still be landfilled.

The main disadvantage of incineration is that emissions released into the environment are harmful [10]. Dioxins and furans, for example, are released through the incinerator stack and are carcinogenic. Trace metals are also released and these can cause respiratory problems [11]. These emissions, however, can be reduced to minimum through the use of baghouses and scrubbers when used as air pollution control devices $[8,12,13]$. The use of a scrubber can reduce the dioxin and furan emissions by a total of $86 \%$ [14].

A high level of technical competence is required in designing, operating and monitoring of any incineration facility in order to minimize fuel consumption and shorten the incineration cycle time [2]. This is because an incineration facility is an integrated activity involving a number of process operations (feed reception, control and preparation-actual combustion stage-treatment of combustion products, waste gases and residues). The options available within these process operations can be combined in various ways to meet the technical needs of a wide range of circumstances ${ }^{1}$. The major problem is, however, the changes in the incineration or combustion duration and lower temperature in the chambers, which causes continuous fuel flow into the burners. The heat loss due to excessive air supply lowers the temperature, also leading to excessive fuel consumption.

Exhaust gas temperatures from the incineration systems are typically as high as $1100^{\circ} \mathrm{C}$ [10]. At these temperatures, most of the operating costs can be related to fuel costs. Waste heat recovery represents one method for off-setting the operating costs. A properly designed temperature control system is required so that the fuel supply is stopped once the pre-selected and set temperature is reached. The fuel is used up only when the temperature drops below this value. This provides a saving in fuel consumption in a long run, despite the high costs related to the installation of the control system. In any case, the total operating cost is high due to fuel [6], electricity, labour, maintenance and supervision. The major incinerator requirements are often referred to as the 3Ts: the Tem-

\footnotetext{
${ }^{1}$ http://www.basel.int/meetings/sbc/workdoc/old\%20docs/tech-d10.pdf
}

perature must be high enough, there must be enough Turbulence in the combustion gas mixture (provided by use of electric blowers) and it must be held at these conditions for a long enough Time [15]. The time for incineration has a great impact on the incineration efficiency and fuel consumption, which forms a major part of the study presented in this paper. The time required to complete one combustion cycle is studied in details in this paper as cycle time. Although the cycle time can include waste loading and ash removal, these two operations has no significant effect on fuel and power consumption and hence are not strongly related to operating costs of the medical waste incinerator.

\subsection{Fuel Consumption during Incineration}

Another disadvantage of incinerators is excessive fuel consumption when there is no proper control of temperature and incineration cycle time. High fuel consumption occurs when the operator is trying to burn extremely moist waste, or when too much air is added to the system [6]. It should be noted that water must be evaporated from the wet waste before volatilization can occur. Since heat is not released from the waste until it starts to volatilize, the auxiliary burner must supply the extra energy needed, leading to high fuel consumption. To reduce fuel consumption, the high moisture waste must be limited in any particular load. If the combustion chambers have leaks, excess air will be introduced to the incinerator and increase fuel consumption. Air could enter the incinerator through doors that have become warped due to overheating, or through deformed seals or holes in the incinerator chamber, piping or connections due to corrosion. If excess air is introduced in the primary chamber, the volatile gases will be partially burned in the primary chamber and will not be available to heat the secondary chamber. If excess air enters the secondary chamber, the temperatures will drop and the burner will operate for longer periods even when the temperature control system is well functioning [16].

\subsection{Incineration Cycle Time}

The capacity of an incineration process should be calculated based on overall cycle time for the process to complete all the necessary operations. The cycle time cannot include delays introduced by the operator. Only legitimate process steps constrained by the equipment and techniques employed to operate the process are valid in an assessment of cycle time. The total mass charged during the period is divided by the total cycle time, and the resultant number gives the operating rate or incinerator capacity in $\mathrm{kg} / \mathrm{h}$. It is this number which should then be compared with any capacity [17]. In this study, however, the capacity was established based on combustion times 
only. Thus, the incinerator capacity defined in this study can also be regarded as the combustion rate for the medical waste.

When the incinerator is charged with the appropriate mix and quantity of waste, the operator should close the door, ensure all interlocks are engaged, and start the burn cycle. The burn cycle should not be interrupted by opening the charging door until after the burn is complete and the unit has cooled down. No additional waste should be added to the primary chamber unless the incinerator is equipped with an appropriate ram feed device.

In this study, the incineration cycle time is defined as the time taken from the start to the end of combustion (when the chamber has been cooled to about $250^{\circ} \mathrm{C}$ $300^{\circ} \mathrm{C}$ ). The rate of combustion can be slowed by reducing the quantity of under-fired air. Moreover, the rate of combustion depends on the type of waste charged and composition. In this study, sharps waste and other medical waste were categorized to study the effect of waste composition on the cycle times and diesel oil consumption.

\subsection{Loading Rate for Incinerators}

The waste can be loaded into the incinerator as batches or in a continuous manner. For facilities incinerating more than 26 tons of waste per year, dual chamber controlled air incinerators are the recommended configuration. To establish the quantity of waste incinerated (defined as incinerator capacity), the basic measurement for every incinerator site must be the quantity of waste charged to the incinerator during the year. Because the incinerator is limited to a fixed quantity of waste on every charge, each load should be recorded separately, and the quantities totaled for the year, and preferably weekly and monthly. Such data will also assist the owner in determining waste generation rates in the specific health facility. Incineration plants can be in operation 24 hours a day which allows for increased net waste disposal per day. In hospitals, however, most of the incinerators operate for few hours per day, due low waste generation. However, fuel consumption during hours of operation must be examined. Meanwhile, the duration of combustion could also be minimized to reduce fuel consumption by proper control of the 3Ts [10].

\subsection{Medical Waste Incineration Process Studied}

For the medical waste incinerator studied, the waste is fed in batches into the incinerator primary chamber, where flames around $950^{\circ} \mathrm{C}$ burn the waste in multiple stages [15], as summarized in Table 1. As the waste is burned, ash is produced which is collected for later disposal in a landfill. These systems are capable of incinerating a wide range of wastes and, when properly maintained and op-
Table 1. Design features of the batch medical waste incinerator studied.

\begin{tabular}{ll}
\hline Design feature & Details \\
\hline Number of chambers & $\begin{array}{l}\text { Single-chamber (with afterburner) } \\
\text { Excess air in primary chamber } \\
\text { Air supply }\end{array}$ \\
Excess air in secondary chamber \\
Waste feeding mode & $\begin{array}{l}\text { Batch (one load per cycle, one cycle per } \\
\text { day) }\end{array}$ \\
Ash removal mode & $\begin{array}{l}\text { Batch, daily before loading new batch of } \\
\text { waste }\end{array}$ \\
Air pollution control & $\begin{array}{l}\text { None } \\
\text { Forced air blowers supply air into } \\
\text { Combustion chambers }\end{array}$ \\
Heat recovery system & None \\
\hline
\end{tabular}

erated, will achieve emissions of PCDD/F and mercury below the level of most national and international standards. This system is equipped with an after burner connected to the chimney and sized to provide a residence time of at least one second at a temperature higher than $900^{\circ} \mathrm{C}$, to ensure complete combustion and minimize PCDD/F emissions [16]. The primary chamber, however, should be operated in the temperature range specified by the manufacturer (typically $500^{\circ} \mathrm{C}$ to $800^{\circ} \mathrm{C}$ ).

\section{Materials and Methods}

\subsection{Design Features of the Assessed Incinerator}

The old Temeke hospital incinerator was a simple facility comprising of a cylindrical combustion chamber with an opening for waste feeding and a chimney for smoke outlet, as shown in Figure 1. The secondary burner (or afterburner) is connected to the chimney, which acts as a secondary chamber. The waste is loaded on the grate and ashes are collected below the grate. Such units are not suitable in terms of combustion efficiency and environmental acceptance. The first chamber performs pyrolytic destruction of the waste and final combustion of gases takes place in the secondary chamber. This incinerator was designed mainly for destroying placentas from labor wards, but due to scarcity of incineration facilities, it was used for destroying all medical waste generated in a district hospital, which implies that the incinerator was being overloaded.

The fuel consumption was alarmingly high, about 20 $40 \mathrm{~L} / \mathrm{h}$, which necessitated investigation. The maximum temperature was about $700^{\circ} \mathrm{C}$ only in the secondary chamber, but the primary chamber temperature was only about $400^{\circ} \mathrm{C}-500^{\circ} \mathrm{C}$. The incinerator had the capacity to burn only about 10 placentas per day, but was usually loaded from 55 to $214 \mathrm{~kg}$ of mixed medical waste due to lack of incineration facilities. Lack of air pollution control device made the whole equipment less useful. The 


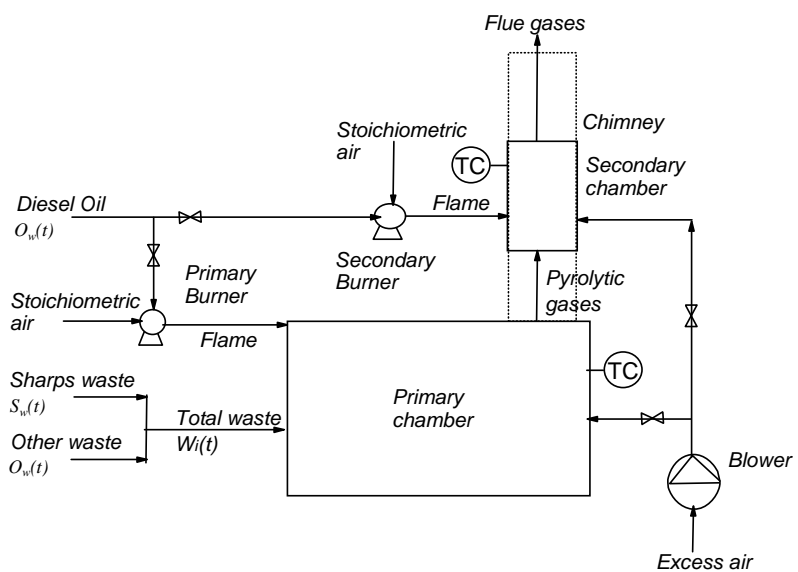

Figure 1. Design features of the assessed incinerator.

incinerator was located in densely populated area, which made the smoke problems to be a continuous nuisance to the nearby community. Other incinerator problem in relation to its design was fluid leakage (blood) from the drying placentas in the primary chamber onto the floor which caused aesthetic view and odorous environment.

\subsection{Experimental Model Formulation}

Figure 1 shows the process flow sheet for the double chamber incinerator used in this study. In this model, the input parameters studied include: Sharps waste loaded in primary chamber, $S_{w}(t)$; Other waste loaded in primary chamber, $O_{w}(t)$; Total diesel oil consumed per cycle by the two burners, $D_{o}(t)$, and the incineration cycle time, $T_{c}(t)$, where $t$ denotes time in days. The quantity of air through the burners (stoichiometric air) and blower (excess air) were not determined. The multi-variable time series recorded for $N=654$ days, can be expressed as per Equation (1), in which, each parameter was recorded separately:

$$
X_{i}(t)=\left\{\begin{array}{l}
S_{w}(t) \\
O_{w}(t) \\
D_{o}(t) \\
T_{c}(t)
\end{array}\right.
$$

The total weight of the waste loaded into the primary chamber, $W_{i}(t)$, was determined by adding the amounts of sharps waste and other waste as shown in Equation (2):

$$
W_{i}(t)=S_{w}(t)+O_{w}(t)
$$

From Equation (2), the mass fraction of other waste and sharps waste, $X$ and $Y$, respectively, were determined as per Equation (3):

$$
X=\frac{O_{w}}{W_{i}} \text { and } Y=\frac{S_{w}}{W_{i}}
$$

\subsection{Data Collection Methods}

The data collection took about 22 months (654 days) from August 2007 to May 2009. The operators were trained on how to conduct the data recording exercise. Medical waste was segregated into different containers at the points of generation (plastic bags for other waste and sharps boxes for sharps waste), collected for the whole day, weighed and recorded (kg/day) ready for incineration. The checklist was designed to suit the type of data to be collected, in which the amounts of sharps waste loaded (kg/day), other waste loaded (kg/day), diesel oil used (L/day) and incineration cycle time (h) were recorded. One incineration cycle was performed per day, such that kg/cycle or kg/day and L/cycle or L/day represents the same quantity.

\subsection{Time Series Analysis Techniques}

The total waste incinerated per day, $W_{i}$, was defined as the total weight of waste (both sharps and other waste, in $\mathrm{kg}$ ) loaded into the incinerator primary chamber per day (also called incineration rate). The average medical waste incinerated per day, $W$, for the whole period $(N=654$ days), was computed as per Equation (4):

$$
W=\frac{\sum W_{i}}{N}
$$

Moreover, the average values for $S_{w}(t), O_{w}(t), D_{o}(t)$ and $T_{c}(t)$ were determined using Equation (5):

$$
X=\frac{\sum X_{i}}{N}
$$

The incineration capacity, $C_{p i}$, defined as the $\mathrm{kg}$ total waste incinerated per hour, based on the cycle time, was determined as per Equation (6):

$$
C_{p i}=\frac{W_{i}}{T_{c}}
$$

The fuel effectiveness, $F_{e}$, defined as $\mathrm{kg}$ of total waste incinerated per liter of diesel consumed, forms assessment criteria for incinerator performance which represents the waste properties (moisture content and composition), burner efficiency (heat output in $\mathrm{kW}$ ), cycle time, and chamber size. This was calculated as per Equation (7):

$$
F_{e}=\frac{W_{i}}{D_{o}}
$$

\section{Results and Discussion}

\subsection{Distribution of the Daily Medical Waste Incineration Data}

The statistical analysis of the waste incineration data revealed that the sharps waste ranged between 12 and 60 
kg per cycle, while the other waste ranged between 30 and $154 \mathrm{~kg}$ per cycle. On the other hand, the total weight of the medical waste incinerated ranged between 55 and $214 \mathrm{~kg} / \mathrm{cycle}$. Based on the standard deviation of the time series, the fluctuations were strongest for other waste than for sharps waste, with values of 4.18 and 7.81, respectively. More details on the statistical analysis of the daily incineration data are shown in Table 2.

Figure 2 shows the probability density functions (PDFs) of the daily medical waste incineration data for sharps waste, other waste and total waste. It is evident from Figure 2 that the fluctuations in the daily total medical waste incinerated are primarily caused by inherent changes in the other waste, as the standard deviations are equally high compared to that of sharps waste time series.

The skewness values $\left(S_{k}\right)$ suggest that the other waste and total waste are skewed towards high values (high positive skewness) compared to sharps waste. It should be noted that if $S_{k}=0$, then the frequency distribution is normal and symmetrical, indicating that none of the time series are close to a normal distribution. The positive skewness values (which indicates occurrence of few high values in the waste incineration data) can be attributed to incidences where the waste loaded was wet due to expo-

Table 2. Statistical analysis of the daily medical waste incineration data.

\begin{tabular}{cccc}
\hline Waste category $\rightarrow$ & $\boldsymbol{S}_{w}(\boldsymbol{t})$ & $\boldsymbol{O}_{w}(\boldsymbol{t})$ & $\boldsymbol{W}_{\boldsymbol{i}}(\boldsymbol{t})$ \\
\hline$N$ & 654 & 654 & 654 \\
Mean (kg) & 24.41 & 73.56 & 97.97 \\
Std. Deviation & 4.18 & 7.81 & 9.96 \\
Skewness & 0.913 & 1.186 & 2.118 \\
Kurtosis & 6.81 & 19.14 & 28.25 \\
Minimum (kg) & 12 & 30 & 55 \\
Maximum (kg) & 60 & 154 & 214 \\
Sum (kg) & $\mathbf{1 5 , 9 6 5}$ & $\mathbf{4 8 , 1 0 7}$ & $\mathbf{6 4 , 0 7 2}$ \\
\hline
\end{tabular}

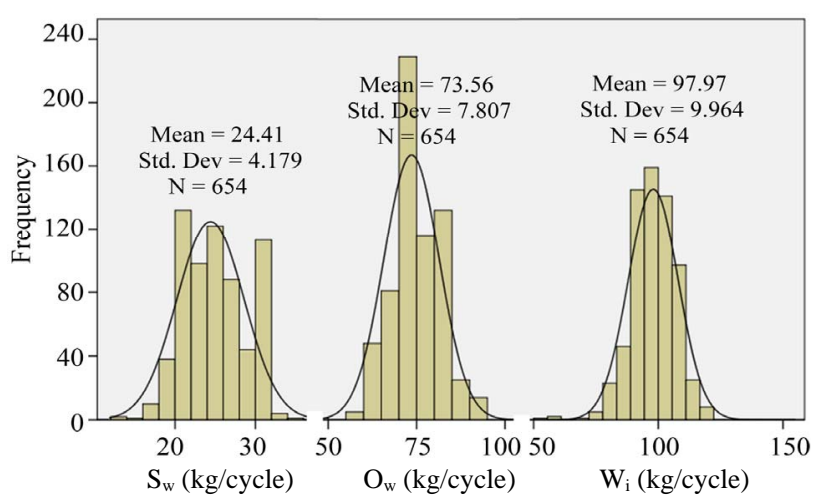

Figure 2. PDF of the daily medical waste loaded in the incinerator. sure to rain, effective waste collection in the hospital, intermittent high medical waste generation rates due to extra ordinary services offered in the hospital and also to large number of deliveries in some of the days studied.

\subsection{Composition of Waste Incinerated (Sharps and Other Waste)}

Incinerators are designed according to the types of wastes they burn. Therefore, understanding the characteristics of different waste streams and hazardous constituents of wastes is necessary to ensure proper selection and design of the thermal process to be used. The characteristics of the waste loaded to the incinerator will affect the temperature profile in the various sections of the incinerator during the burn cycle. These variations will also influence the duration of auxiliary burner operation, especially when the waste is wet.

Wastes with a high percentage of volatile matter (paper, plastics, cotton wool, etc.), will release more volatile gases from the primary chamber than wastes with low percentage of volatile matter. In this study, the waste composition was based on two categories of waste, that is, sharps waste and other waste. The compositions were expressed as $X$ (kg other waste per $\mathrm{kg}$ total waste) and $Y(\mathrm{~kg}$ sharps waste per kg total waste). Figure 3 presents the PDFs of $X$ and $Y$ values observed in this study. It should be noted that $X$ and $Y$ are random variables governed by the fluctuations in the quantities of the incoming waste to the incinerator house. All the incoming waste was loaded such that the incinerator loading reflects the waste collection efficiency from the hospital sections. The sharps waste composition varied between $15 \%$ and $35 \%$, while the other waste varied between $65 \%$ and $85 \%$ with mean values of $25 \%$ and $75 \%$, respectively. The incinerator operator could not decide how much of the waste type to load, as all the waste received must be incinerated. Thus, this data represents the true waste generation characteristics of the district hospital. The similarity in the PDFs between $X$ and $Y$ is based on the fact that the data are dependent determined from the same quantity, the total waste, $W_{i}$ (as per Equation (2)).

\subsection{Variations in the Diesel Oil Consumption during Medical Waste Incineration}

The diesel oil consumption was observed to vary between 20 and $40 \mathrm{~L} / \mathrm{cycle}$, although higher values up to 70 $\mathrm{L} /$ cycle were observed in fewer cases. Most of the cycles were conducted at $30 \mathrm{~L} /$ cycle (74\%) as shown in Figure 4, followed by $40 \mathrm{~L} /$ cycle (18\%) and $32 \mathrm{~L} /$ cycle $(5 \%)$. The cycles operated at $20 \mathrm{~L} /$ cycle were very few (3\% only). Thus, the incinerator performance was poor as the fuel consumption was too high, at an average of $32 \mathrm{~L} /$ day. This was contributed mainly by lack of temperature con- 


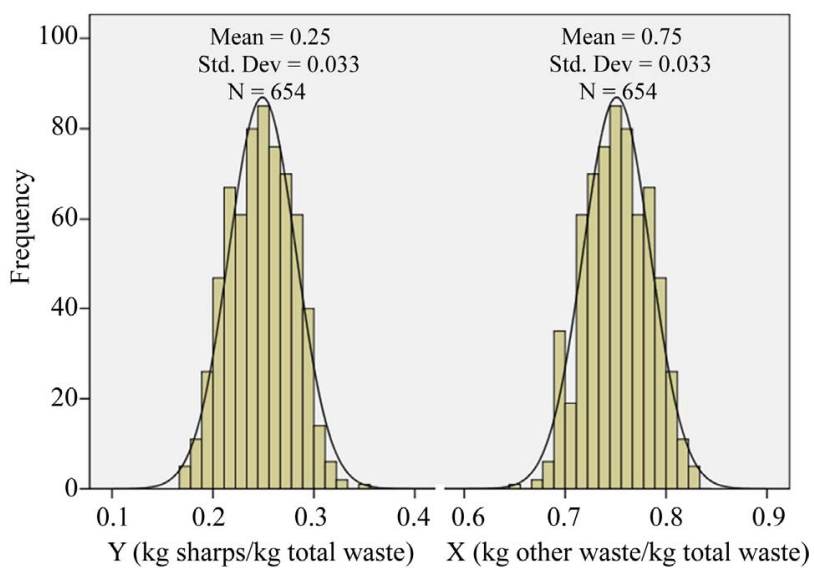

Figure 3. Histograms of the waste composition data $(N=$ 654).

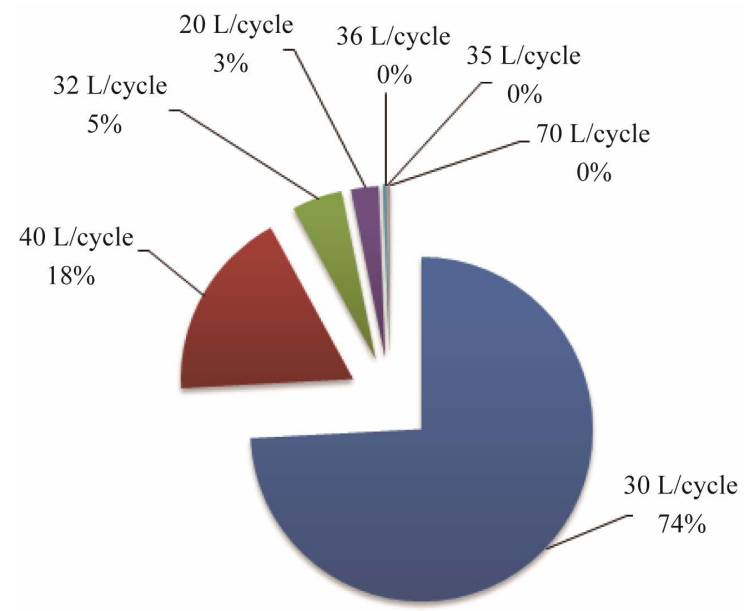

Figure 4. Frequency distribution of diesel oil consumption data.

trol system as the required temperature of $850^{\circ} \mathrm{C}-950^{\circ} \mathrm{C}$ were never reached, leading to continuous fuel flow into burners. Also, burning of wet waste, poor chamber design and poor operator skills were the contributing factors.

\subsection{Variations in the Incineration Cycle Time during Medical Waste Incineration}

Figure 5 shows the frequency chart for incineration cycle time data. Most of the cycles (80\%) were operated for 3 hours and few (17\%) for 4 hours, while fewer cycles were operated for 2 hrs (3\%). For the waste load of 55 $214 \mathrm{~kg}$, even a 2-hour cycle time is too long, as the waste should be completed within 30 - 40 minutes for a well performing incinerator. Again, the problem of chamber design, wet waste (exposed to rain) poor operator skills, contributed to the poor incinerator performance. Extended cycle times leads to excessive fuel consumption and increased running costs.

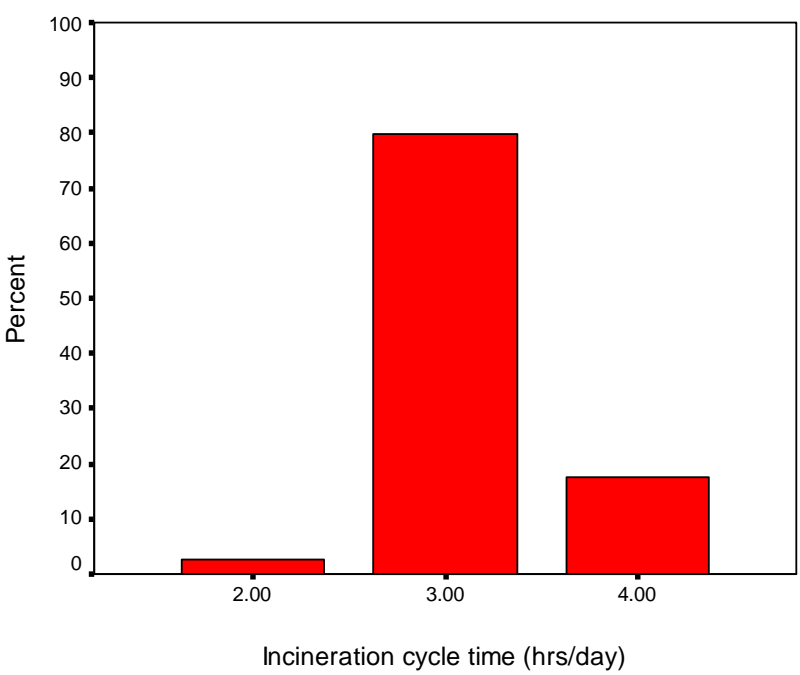

Figure 5. Frequency distribution of incineration cycle time data.

\subsection{Probability Density Functions for the $D_{o}(t)$ and $T_{c}(t)$}

Figure 6 presents the PDFs of $D_{o}$ and $T_{c}$ for the incinerator studied. The highest frequency for diesel oil consumption was observed at $30 \mathrm{~L} /$ day and 3 hours for cycle times. The two PDFs are similar because of dependency of the two data types due to the fact that the burners were operating all the time. This was caused by lower chamber temperatures than the set values, caused in turn by poor chamber design, loading wet waste, and poor operator skills. A strong dependency between $D_{o}$ and $T_{c}$ was observed with a linear relationship having a slope of $10 \mathrm{~L} / \mathrm{h}$ corresponding to the burner diesel oil consumption rate, when the temperature control is not installed. Thus, lower temperature in the combustion chamber lowered the incinerator performance considerably, as the fuel consumption rate is increased.

\subsection{Incinerator Capacity}

The incinerator capacity ( $\mathrm{kg}$ total waste incinerated per hour), $C_{p i}$, was also studied to assess the performance of the incinerator. To establish the time series for tons per year, the $W_{i}$ and $T_{c}$ data were multiplied. The number of days used to establish annual incineration capacity was 365 days/year, since the data collection was conducted every day. Figure 7 presents the PDF of the incinerator capacity data in $\mathrm{kg} / \mathrm{h}$. The mean value of $C_{p i}$ was 31.43 $\mathrm{kg} / \mathrm{h}$, with the values ranging between 13.75 and 52.50 $\mathrm{kg} / \mathrm{h}$. In terms of tons/year the mean value was 34.4 tons/year with the values ranging between 15.06 and 57.49 tons/year. Based on the data collected for 22 months covering 653 days, the total waste incinerated was 64 tons (as revealed also in Table 2), which corresponds to an average incinerator capacity of 35.7 tons per year. Re- 

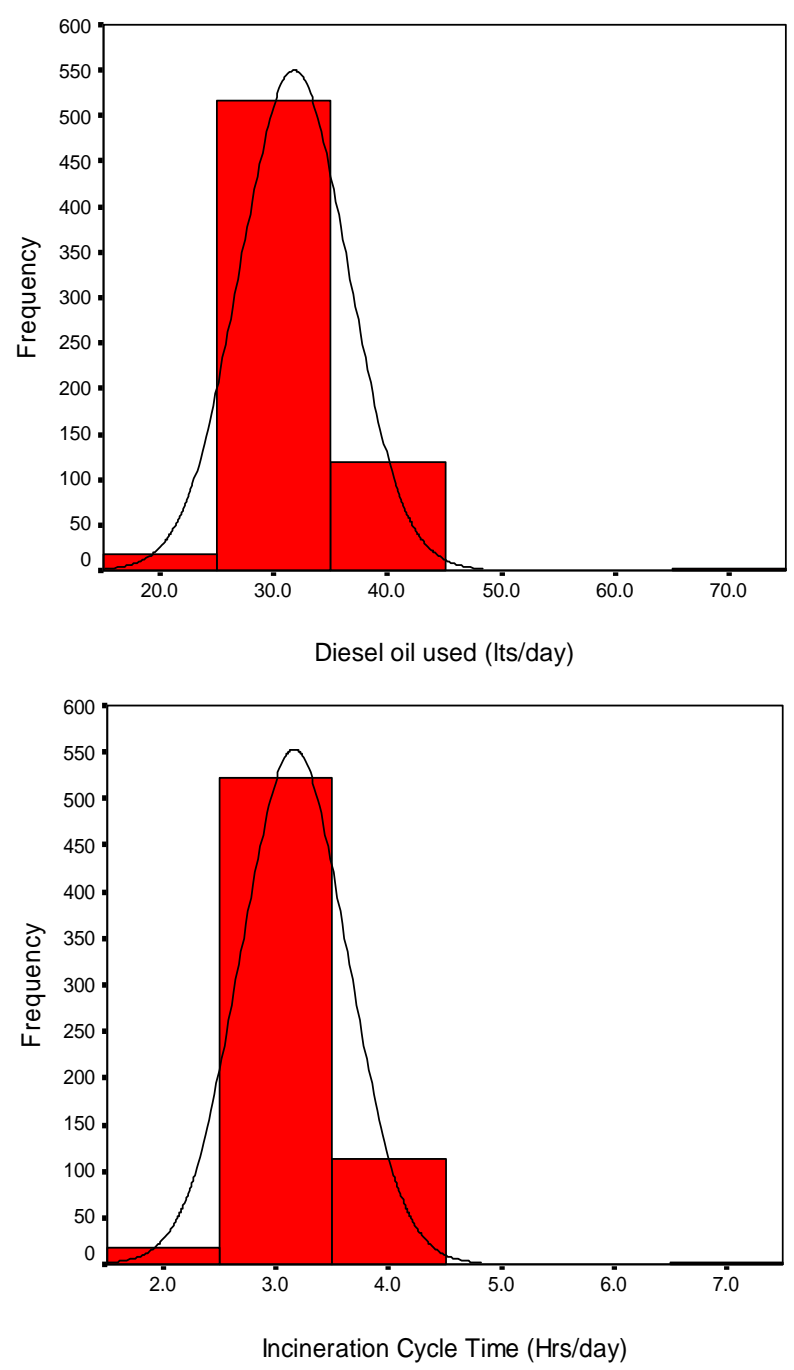

Figure 6. Probability density functions for the diesel oil consumption and incineration cycle time data.

sults show further that the capacity of the incinerator was above 26 tons/year, which requires a double chamber system according to literature [16]. However, the secondary chamber was not provided, and instead, an afterburner connected on the chimney was used. Moreover, this capacity is low for a district hospital, whereby if all the medical waste is collected effectively, the incinerator would not sustain. The lower values of $C_{p i}$ were also caused by loading waste in corrugated paper boxes which occupies large volume with small overall weight, $W_{i}$.

\subsection{Dependence of Cycle Time on Sharps and Other Waste Incinerated}

The relationship between incineration cycle time and waste incinerated, both sharps and other waste was analyzed as shown in Figure 8. On average the incineration process took about 3 hrs to destroy the waste loaded, (refer to vertical axis), presented as flat surface on the

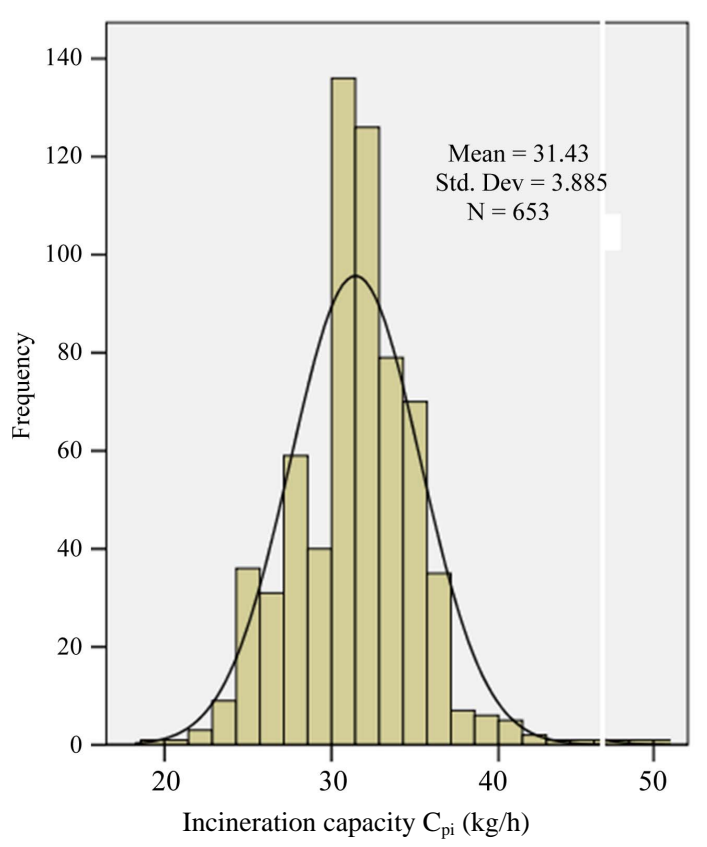

Figure 7. Probability functions for incinerator capacity data.

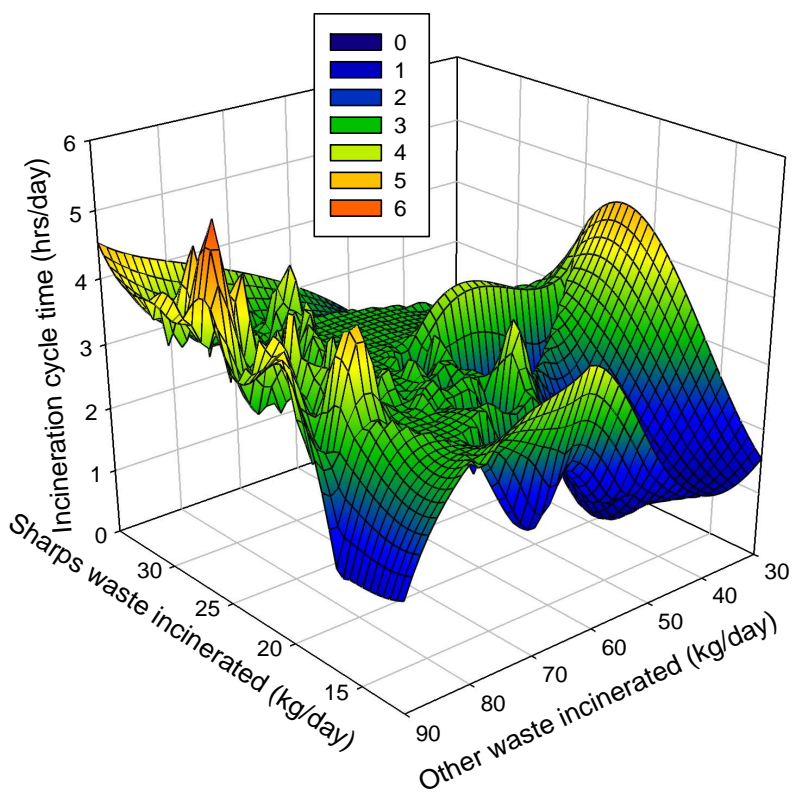

Figure 8. Variation of the incineration cycle time with sharps and other waste incinerated.

three-dimensional plot. The waste which took between 1 and 2 hrs to be destroyed was dry waste with high combustible characteristics likely to be papers, gauze, gloves, syringes etc., while the medical waste with high moisture content took about 4 hrs to 6 hrs to be destroyed causing spikes as can be seen in Figure 8, likely to be pathological waste and other wet and non-combustible materials. The higher cycle time leads to more fuel consumption which increases the running cost of incinerator. 


\subsection{Dependence of Fuel Consumption on Sharps and Other Waste Incinerated}

Diesel oil used was studied in relation to sharps waste and other waste incinerated as summarized in Figure 9. The results showed that, some of the cycles used little amount of diesels (about $10 \mathrm{~L}$ ) while other cycles used more diesel (about $50 \mathrm{~L}$ ). On average, most of waste were destroyed using $30 \mathrm{~L}$ of diesel oil. The study also observed troughs which correspond to lower fuel consumption due to variations in amount of waste loaded, waste composition, moisture content, etc. Thus, diesel oil used for incineration should be controlled to reduce the running cost of incinerator. This can be attained by proper process control in terms of air supply and temperature settings.

Comparing Figures 8 and 9 the results revealed that, as longer time is used in the incineration process more fuel is consumed, the situation which increases running cost for the incinerator. It is then recommended to hospitals: to segregate their waste at point of generation; to have the operator with knowledge especially on how to control temperature, loading a good combination of sharps and other waste, removing non-combustible materials during segregation at generation points, constructing a standard waste collection bay to take care of weather variations especially rain, which increases moisture content in the waste.

\subsection{Analysis of Fuel Effectiveness during Incineration}

The fuel effectiveness data was assessed by plotting a PDF (Figure 10) so as to establish the range and frequency distribution of the values. The mean value of $F_{e}$ was $3.13 \mathrm{~kg}$ waste per litre of diesel, which is too low. The values ranged between 1.38 and $5.25 \mathrm{~kg} / \mathrm{L}$. The distribution is closer to the normal distribution with skewness of 0.523. The lower values of $F_{e}$ can be attributed to the loading wet waste exposed to rain, which leads to higher $D_{o}$ values, and also due to smaller chamber size such that the overall weight $W_{i}$ was low. In some cases, lower capacity was observed because the waste is collected in boxes made of corrugated paper, which occupies space in the chamber, leading to lower $W_{i}$ values and hence lower $F_{e}$.

\subsection{Dependency of Fuel Effectiveness on Total Waste Incinerated}

The total waste incinerated per day was studied in relation to fuel consumption. The results showed that, about 70 to $120 \mathrm{~kg}$ of waste was incinerated per day, consuming 20 to $40 \mathrm{~L}$ of fuel per cycle. However, as the amount of waste incinerated increases $\left(W_{i}\right)$ the fuel effectiveness, $F_{e}$ increases as well. Four different linear relationships

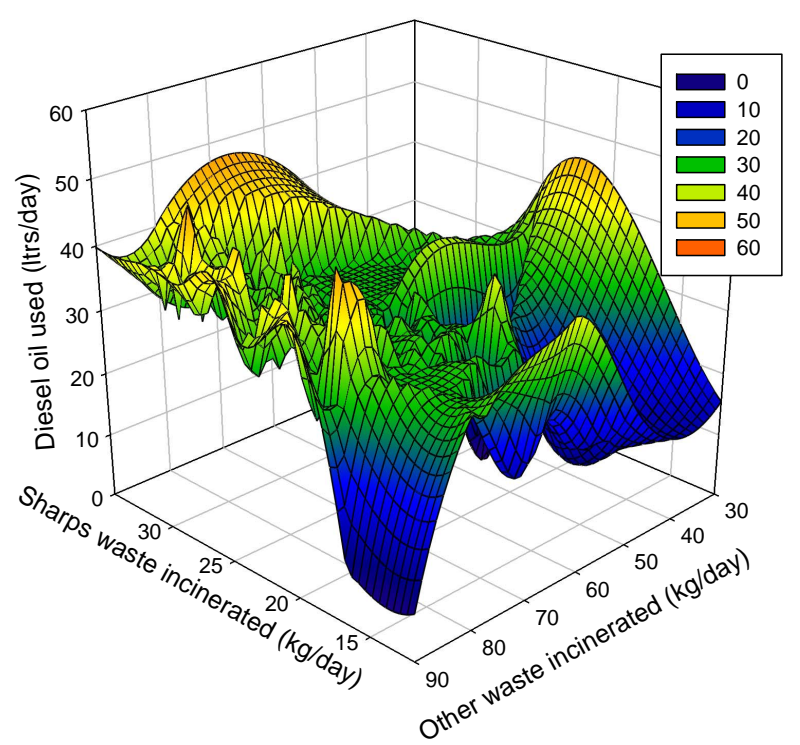

Figure 9. Variation of diesel oil used with sharps and other waste incinerated.

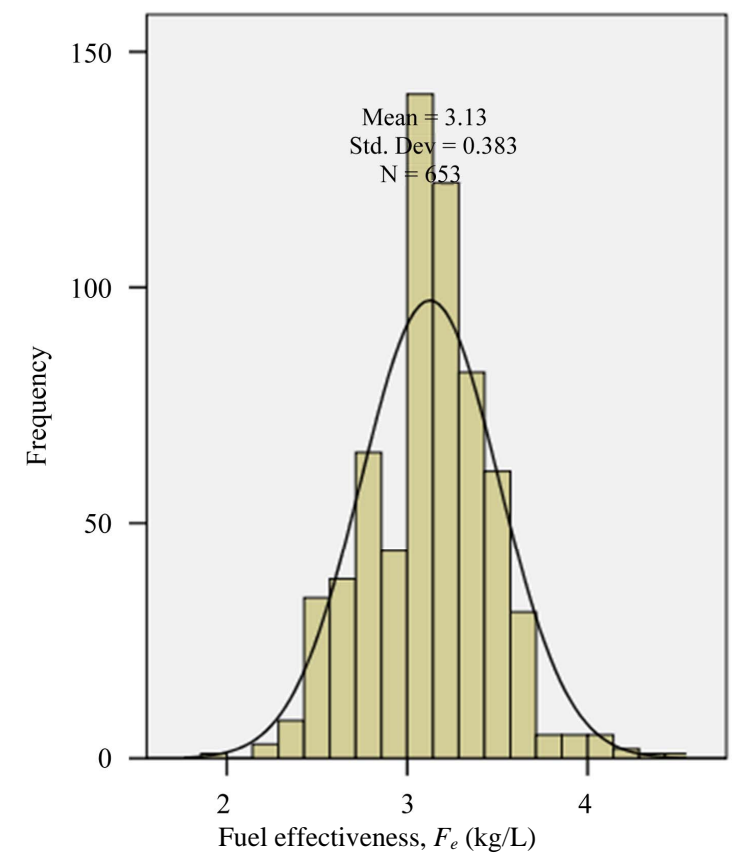

Figure 10. Distribution of fuel effectiveness data.

were observed between $F_{e}$ and $W_{i}$, depending on the average fuel consumption, as shown in Figure 11.

The fuel effectiveness data which was represented by a linear equation $y=0.05 x$ consumed $20 \mathrm{~L}$ diesel/cycle indicating the lowest fuel consumption rate for the incinerator under study. This model fuel consumption rate, $D_{o}$ $=20 \mathrm{~L} /$ cycle, represents the highest fuel effectiveness values as shown in Figure 11. Such incinerator performance was attributed to dry waste loaded into the chamber, which corresponds to dry days, few deliveries in the hospital, (that is, few placentas destroyed) properly seg- 


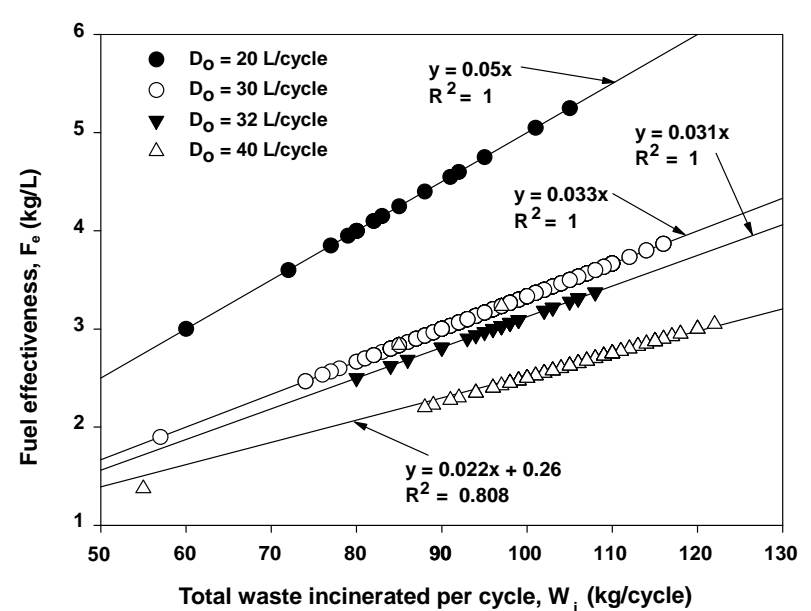

Figure 11. Variation of fuel effectiveness with total waste loaded into the incinerator.

regated waste, etc. However, such cycles were very few as depicted by only 17 data points.

Most of the incineration cycles consumed $30 \mathrm{~L} /$ cycle which is depicted by a liner equations $y=0.033 x$ with good fit $\left(R^{2}=1\right)$. These cycles correspond to the waste with average composition of $25.07 \%$ sharps waste, as shown in Table 3 . The fuel consumption rate of 32 $\mathrm{L} /$ cycle, was observed in 34 cycles only, with a linear fit of $y=0.031 x$, also with $R^{2}=1$.

Highest fuel consumption per cycle and lowest fuel effectiveness were among the indicators of poor incinerator performance observed for $D_{o}=40 \mathrm{~L} /$ cycle. The data was correlated using a linear equation $y=0.022 x+$ 0.26 , but with a poor fit of $R^{2}=0.808$. The poor fit is attributed to the fact that many factors were acting on the process performance. This observation was further attributed to wet waste due to rain and also due to poor segregation of waste loaded into the incinerator. The waste storage bay had no roof and its sides were made up of wire mesh only. Another reason for such a poor performance was poor segregation of waste, in which noncombustible materials in bags or boxes are loaded into the incinerator leading to longer incineration cycles and larger fuel consumption. Table 3 summarizes the data presented in Figure 11.

Based on Figure 11, the fuel oil consumption rates were in four model values, that is, 20, 30, 32 and 40 $\mathrm{L} /$ cycle. For each of these model values, the cycles operated were counted as shown in Table 3. The $D_{o}=30$ $\mathrm{L} /$ cycle had the largest number of cycles or frequency (74\%) as revealed in Figures $\mathbf{3}$ and $\mathbf{5}$ and also by many data points in Figure 11. The average cycle times for each value of $D_{o}$ were determined as shown in Table 3 . Similarly, the average composition of the medical waste loaded is provided (as $X$ and $Y$ ). With values of $X, Y$ and $W_{i}$ in Table 3, the average values of $O_{w}$ and $S_{w}$ for each model value of $D_{o}$ can be established (Equation (3)). Each model fuel consumption, the average $\mathrm{kg}$ of medical waste incinerated and fuel effectiveness were also determined as shown in Table 3.

The dependence of diesel oil consumption on the fractions of sharps and other waste is evident from Table 3, details of which require further investigation. Based on the data presented in Table 2, it is also evident that the fuel consumption, $D_{o}$ (L/cycle) strongly depends on the $\mathrm{kg}$ of total waste loaded into the incinerator, $W_{i}$. To investigate this relationship further, the $D_{o}$ values (Figure 11 and Table 3) were plotted against the corresponding average values of each waste category $\left(S_{w}\right.$ and $\left.O_{w}\right)$ and also against the average total waste, $W_{i}$, corresponding to the model diesel oil consumption values as shown in Figure 12. Linear relationships were observed, and fitted accordingly.

The equations of best fit gives the diesel oil consumption per cycle for a given average waste type loaded $\left(S_{w}\right.$ or $\left.O_{w}\right)$ and total waste $\left(W_{i}\right)$ values, with very high $R^{2}$ values. However, since the diesel oil consumption values were very high, a similar analysis for improved systems is required.

\subsection{The effect of Sharps and Other Waste Loaded on Fuel Effectiveness}

It was further observed that the highest $F_{e}$ values were observed when $S_{w}$ is highest as shown in Figure 13. A range of $O_{w}$ where $F_{e}$ is highest also at high $S_{w}$ was about 80 - $120 \mathrm{~kg} / \mathrm{cycle}$. Lower $F_{e}$ values were observed corresponding to $S_{w}=30-40 \mathrm{~kg} / \mathrm{cycle}$, caused by wet waste loaded and/or poor waste segregation in the different hospital sections. A spike in $F_{e}$ for $O_{w}>120 \mathrm{~kg} /$ cycle and $S_{w}>20 \mathrm{~kg} /$ cycle can be attributed to dry waste loaded.

\section{Conclusions}

Based on the above findings, it can be concluded that:

1) The sharps waste composition for the medical waste incinerated varied between $15 \%$ and $35 \%$, while the other waste varied between $65 \%$ and $85 \%$ with mean values of $25 \%$ and $75 \%$, respectively.

2) The results revealed poor performance of the incinerator due to higher fuel consumption (above $30 \mathrm{~L} /$ cycle).

3) The incineration cycle times were observed to range between 2 and 4 hours, all of which were too high for the loading rates observed (60 - $120 \mathrm{~kg}$ ).

4) A strong dependency of $D_{o}$ on $T_{c}$ was observed due to lack of temperature control leading to continuous fuel flow into the burners (at $10 \mathrm{~L} / \mathrm{h}$ ), caused by low temperature in the chambers below the set points of $600^{\circ} \mathrm{C}-700^{\circ} \mathrm{C}$ in the primary chamber and $950^{\circ} \mathrm{C}$ in the secondary chamber.

5) The incineration capacity was very low compared to other incinerators in terms of tons per year. 
Table 3. Analysis of incineration cycles based on fuel effectiveness.

\begin{tabular}{|c|c|c|c|c|c|c|c|c|c|c|c|}
\hline & & & & & & wast & & & & & \\
\hline & & & Number of & & & g was & & & & & \\
\hline & & & cycles & $I_{c}$ (III) & & $=a x+$ & & $Y=\frac{\mathrm{S}_{w}}{W}$ & $X=\frac{U_{w}}{W}$ & $W_{i}(\mathrm{~kg})$ & $F_{e}(\mathrm{Kg} / \mathrm{L})$ \\
\hline & & & & & $\mathbf{a}$ & b & $R^{2}$ & & & & \\
\hline 1 & 20 & & 17 & 2.0 & 0.050 & 0 & 1 & 0.2291 & 0.7709 & 84.2 & 4.21 \\
\hline 2 & 30 & & 482 & 3.01 & 0.033 & 0 & 1 & 0.2507 & 0.7493 & 96.5 & 3.22 \\
\hline 3 & 32 & & 34 & 3.06 & 0.031 & 0 & 1 & 0.2443 & 0.7557 & 97.2 & 3.04 \\
\hline 4 & 40 & & 117 & 3.93 & 0.022 & 0.26 & 0.808 & 0.2457 & 0.7543 & 105.2 & 2.63 \\
\hline & $\begin{array}{l}\text { rks: } \\
\text { l. } \\
\text { 2. } \\
\text { i. }\end{array}$ & $\begin{array}{l}\text { Dry } \\
\text { Mo } \\
\text { Ave } \\
\text { We }\end{array}$ & $\begin{array}{l}\text { aste, low fract } \\
\text { of cycles, aver } \\
\text { ge fuel consun } \\
\text { vaste, excessiv }\end{array}$ & $\begin{array}{l}\text { of sharps } \\
\text { fuel cons } \\
\text { on. } \\
\text { el consur }\end{array}$ & tion. & & & & & & \\
\hline
\end{tabular}

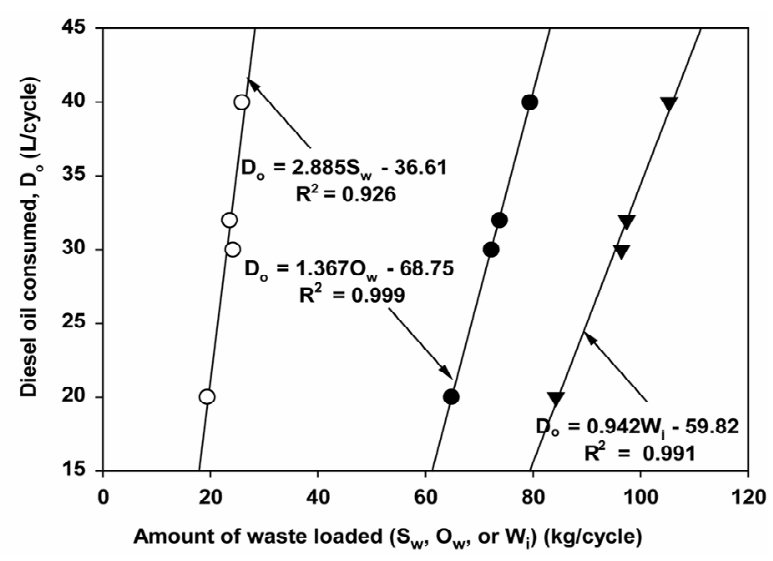

Figure 12. Predicting diesel oil consumption (L/cycle) from average waste loaded (kg/cycle).

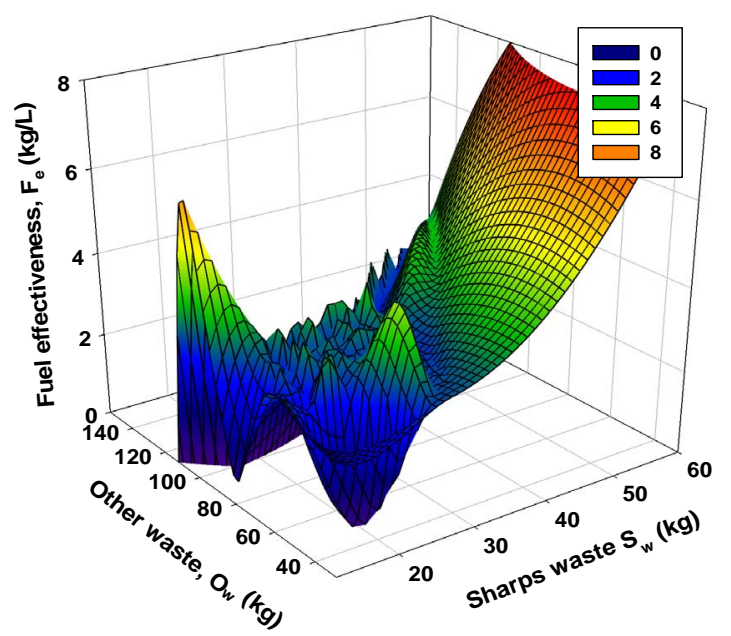

Figure 13. Variation of fuel effectiveness with sharps waste and other waste loaded into the incinerator.

6) This paper gives an insight on the factors affecting incinerator performance assessed based on diesel oil consumption and cycle times.

7) It can be generalized that the incinerator perfor- mance was poor due to several factors ranging from poor incinerator design, operator skills, waste management practices, waste storage practices, etc.

\section{Acknowledgements}

The completion of this study has been the results of assistance received from Temeke Municipal Council health office in particular Temeke hospital medical officer in charge, Health Officer and the incinerator operator for their assistance in data collection.

\section{REFERENCES}

[1] Q. Wang, "Aspects of Pretreated Hospital Waste Biodegradation in Landfills," Proceedings of 7th International Landfill Symposium, Cagliari, 2004, pp. 59-66.

[2] T. Jeremy and A. Honor, "The Health Effects of Waste Incinerators," The 4th Report of the British Society for Ecological Medicine Moderators, 2005.

[3] S. Singh and V. Prakash, "Toxic Environmental Releases from Medical Waste Incineration,” Environmental Monitoring, Vol. 132, No. 1-3, 2007, pp. 67-81. doi:10.1007/s10661-006-9503-3

[4] E. Gidarakos, M. Petrantonaki, K. Anastasiadou and W. Schramm, "Characterization and Hazard Evaluation of Bottom Ash Produced from Incinerated Hospital Waste," Journal of Hazardous Materials, Vol. 172, No. 2-3, 2009, pp. 935-942.

[5] DEA, "Danish Energy Authority: Danish Energy Statistics 2005," 2007.

http://ens.dk/graphics/Publikationer/Statistik_UK/Energy_ statistics_2005/index.htm

[6] L. J. Zhao, F.-S. Zhang, M. J. Chen, Z. G. Liu, D. Bo and J. Z. Wu, "Typical Pollutants in Bottom Ashes from a Typical Medical Waste Incinerator,” Journal of Hazardous Materials, Vol. 173, No. 1-3, 2009, pp. 181-185.

[7] S. V. Manyele, "Medical Waste Management in Tanzania: Current Situation and the Way Forward," African Journal of Environmental Assessment and Management, Vol. 8, 2004, pp. 74-99. http://ajeam-ragee.sl-writers-series.org/ 
[8] S. V. Manyele, "The Role of Engineering in Solving Medical Waste Incineration Problems in Tanzania," Institution of Engineers Tanzania (IET) Annual Conference, 1-2 December 2005, Arusha, 2005, pp. 53-67.

[9] F. Powell, “Air Pollutant Emissions from the Incineration of Hospital Wastes: The Alberta Experience,” Journal of the Air Pollution Control Association, Vol. 37, No. 7, 1987, pp. 836-839.

[10] IAEA, "Design and Operation of Radioactive Waste Incineration Facilities,” A Safety Guide, Safety Series No. 108, Vienna, 1992.

[11] R. R. Groner, "The Chemical Transformation of Solid Wastes,” AICHE Symposium Series, Vol. 68, No. 122, 1972, pp. 28-39.

[12] J. J. Santoleri, "Design and Operating Problems of Hazardous Waste Incinerators,” Environmental Progress, Vol.
4, No. 4, 2009, pp. 246-251. doi:10.1002/ep.670040408

[13] S. V. Manyele, “Toxic Acid Gas Absorber Design Considerations for Air Pollution Control in Process Industries,” Educational Research and Review, Vol. 3, No. 4, 2008, pp. 137-147.

[14] R. Walter, “Combustion and Incineration Processes,” 3rd Edition, Marcel Dekker, New York, 2002.

[15] V. J. Landrum, "Medical Waste Management and Disposal,” 2009. http://books.google.co.tz/books/

[16] Environment Canada, “Technical Document for Batch Waste Incineration,” 2011. http://www.ec.gc.ca/gdd-mw/

[17] SEPR (Scottish Environmental Protection Regulation), 2003.

http://www.scotland.gov.uk/Publictions/2005/04/1914035 4/04040 